\title{
THE IMPACT OF ORGANIZATIONAL STRESS ON THE HUMAN RESOURCES FROM THE HEALTH SYSTEM DURING COVID-19 PANDEMIC
}

\author{
Ana-Madalina Potcovaru \\ Bucharest University of Economic Studies, Bucharest, Romania \\ ana.potcovaru@amp.ase.ro
}

\begin{abstract}
This article shows the impact of organizational stress on the human resources from the health system. The research wants to highlight the main stressors factors among the medical staff, physicians, and assistants from Târgoviște Emergency Hospital from Dâmbovița County and to determine if the organizational stress affects the personal life of the employees. Understanding the sources of stress and reducing them has a great impact on job satisfaction and on the relationship patient-physician.

Also, the article presents the impact of the COVID-19 on the health care workers from a psychological point of view. Coronavirus disease 2019 (COVID-19) affected global mental health.
\end{abstract}

Keywords: organizational stress, job satisfaction, health system, human resources, Coronavirus disease 2019 (COVID-19)

\section{INTRODUCTION}

On March 11, 2020, the World Health Organization declared the COVID-19 outbreak a pandemic (WHO, 2020). Understanding the psychological impact of the COVID-19 outbreak among health care workers is crucial in guiding policies and interventions to maintain their psychological well-being. (Tan et al., 2020). Among the stress factors, Coronavirus disease 2019 caused a great panic and affected global mental health of the entire population.

Stress is part of the daily life of everyone. Stress is an important source of professional exhaustion. Several studies have been done to highlight the impact of the stress on job satisfaction and on the health of the employees. The studies determine that stress has a negative impact on job satisfaction and on health. 
Organizational stress is defined as a rapidly expanding field, characterized by disagreements about terminology and definitions. (Kahn \& Byosiere, 1992). Job insecurity influences both mental and physical health. There is an adverse effect of job insecurity on workers' well-being and health (Nica et al., 2016) There is a paucity on the literature of stress levels of the healthcare workers.

Work dissatisfaction among physicians is a major problem in many countries from all over the world. Physicians' burnout is a major result of dissatisfaction, causing doctors to leave the medical profession and to provide lower quality of care (Acker et al., 2009)

Increased workload is linked to higher stress levels and a reduced job performance and quality of life (Kumar et al., 2012).

Several discontent doctors and healthcare workers can lead to an overall decreased standard of patient care in the hospital (Kumar et al., 2012).

Physician satisfaction is a public health issue (Moshe et al., 2012). Job satisfaction is associated with quality of care, patient satisfaction and patient adherence to medical treatment. Dissatisfied physicians are at higher risk for burnout. This can reduce their clinical work hours and this situation can have consequences on the relationship patient-physician. (Bohannon et al., 2000). Career satisfaction varies by specialty, income, region and age. (Leigh et al., 2002).

\subsection{The impact of the Coronavirus disease 2019 (COVID-19)}

It is known a few aspects about the changes in levels of stress, anxiety and depression during this pandemic. Increasing menace of the epidemic led to a global atmosphere of anxiety and depression due to disrupted travel plans, social isolation, media information overload and panic buying of necessity goods (Ho et al., 2020)

Training for health personnel can help facilitate their better identification and management of patients' psychological distress regarding the Coronavirus disease 2019 (COVID-19). In addition to the fact that doctors need to control their fear that they might be infected with coronavirus, they also need to take care of patients who may have high levels of stress.

Patients, physicians, nurses may experience fear of the consequences of being infected. This could lead to anxiety, stress, and mental problems. It is shown that the psychological impact may be mediated by people's perceptions. (Wang et al., 2020)

The Coronavirus disease 2019 (COVID-19) brought a lot of challenges and concerns and every effort should be put to understand and control the disease. (Troyer et al., 2020)

The stress-adaption model it is particularly important. The first sign of the outbreak it is insomnia. Staff and patients should be educated regarding this aspect. Also, the support, the shared concern and the 
access to realistic information are essential. All efforts to overcome interpersonal isolation have important roles in times of severe strain and stress.

\section{THE DESIGN OF THE RESEARCH}

Târgoviște Emergency Hospital was founded in 1930. In present the hospital has a central headquarter comprising both sections and compartments with beds and without beds. Within the headquarter there is a central hospital, the radiological laboratory, the anatomy-pathological laboratory, the compartment of forensic medicine and a polyclinic composed of 19 medical offices that provide medical services to the whole county. At present the hospital has a total number of 1767 of beds and includes also external sections. (https://www.spitaldb.ro/).

The Orthopedics Department of the County Emergency Hospital was transformed into a reception and treatment space for patients diagnosed with COVID-19. An intensive care unit has been set up here, with 36 beds and high-performance medical equipment. The new pavilion of the county hospital in Târgovişte was modernized in only one month and is organized on three circuits that ensure both the protection of the medical staff and the treatment of those infected with COVID-19. The ward was equipped with command and control panels that allow doctors and nurses to supervise and assist patients.

\section{RESEARCH OBJECTIVES}

The research objectives are to identify the main stressors factors and to determine the impact of the organizational stress on the personal life.

Hypothesis:

1. If medical staff works in an unpleasant environment and faces difficult situations at the workplace, the level of stress is higher

2. Organizational stress affects in a negative way the personal lives of employees Methodology:

To collect the information, I use as a tool the questionnaire and to systemize and interpret the results I used Microsoft Office Excel 2007.

The target group was the medical staff, physicians and assistants from Târgoviște Emergency Hospital from Dâmbovița County. The questionnaire was applied among 296 employees and the answers received were 167. 
The questionnaire was designed to have twenty questions. The first five questions were sociodemographic questions to identify the respondents profile, other five questions were related to the main factors of stress, another five questions were designed to show the relationship between organizational stress and personal life of the employees (to show the interdependence between them), and the last five questions were designed as affirmation and the respondents have to choose the correct answer for them.

\section{THE DATA ANALYSES AND THE MAIN RESULTS}

A total of 167 employees responded to the questionnaire that was distributed among 296 . Of them $63 \%$ of the respondents are female and $37 \%$ are male. Of them $80 \%$ of the respondents are nurses and $20 \%$ are physicians. Regarding the marital status, the married respondents have a rate of $47 \%$.

An important question for the objectives and the purpose of the research was: To what extent do you consider that there is a high level of stress in your workplace?

\section{The level of stress within the hospital}

0

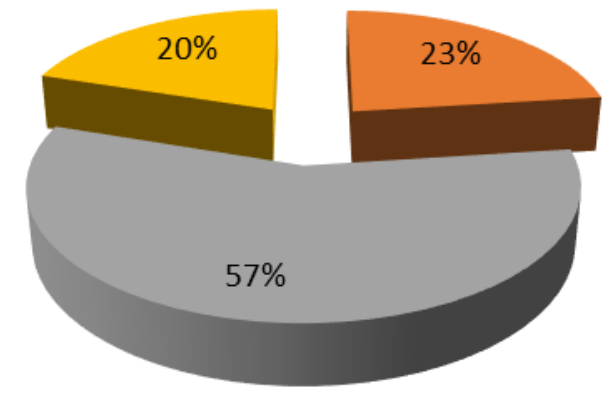

Never

- Rarely

m Often

always

GRAPHIC 1. STRESS LEVEL IN HOSPITALS

Source: Elaborated by the author

The medical staff from this hospital is experiencing a very high level of stress and even if some people do not feel so stress, the stress still exists, because there was not even one person to say that there is no stress at work. As it can be seen the level of stress exists often for $57 \%$ of the respondents and $20 \%$ of the respondents are always stressed.

Another question was related to the employee's satisfaction regarding the work conditions. The question was: How satisfied are you with the working conditions (cleaning, lighting, noise, air conditioning, etc)? 


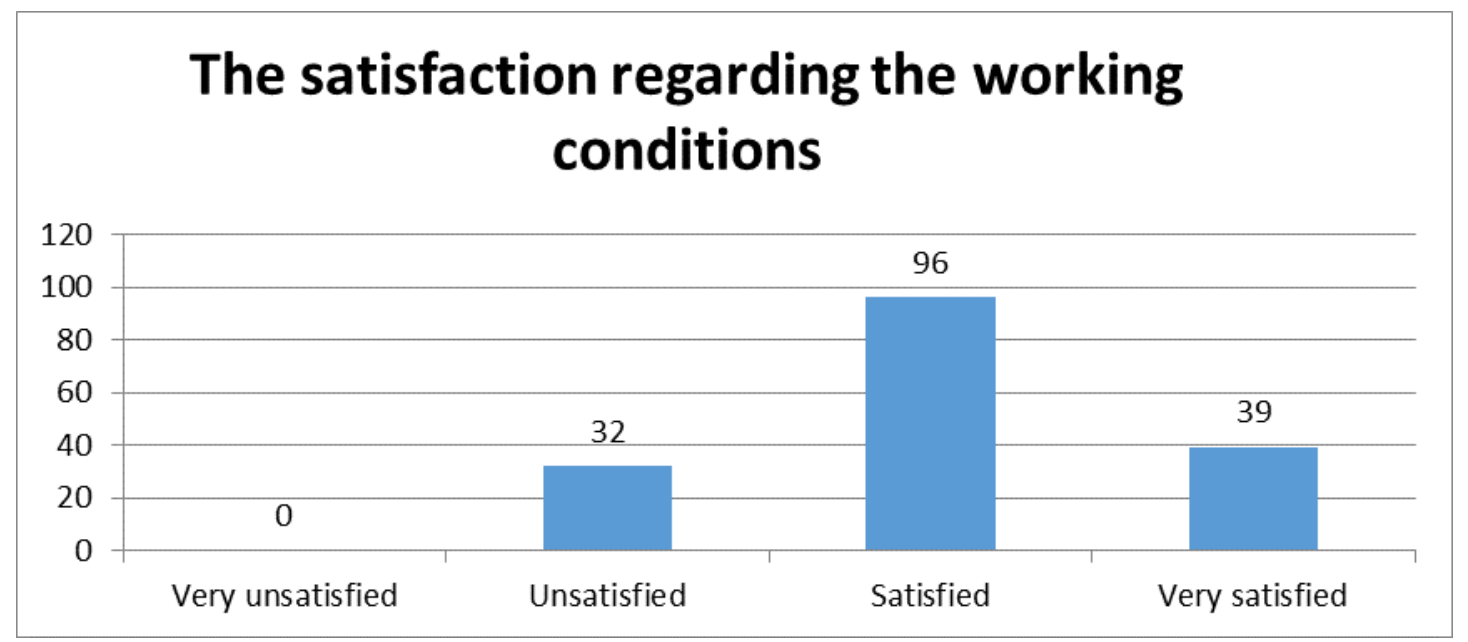

GRAPHIC 2. SATISFACTION REGARDING WORKING CONDITION

Source: Elaborated by the author

As it can be seen the hospital offers good work conditions for the employees. Of the 167 respondents, 96 of them are satisfied with the work conditions.

The main stressors factors for them are: the complexity of the patient's problems, excessive bureaucracy, insufficient time to take important decisions, the large number of patients treated by day, patients misunderstandings and the death of the patients.

Regarding the affirmation: I have tasks that are not found in the job description because there is not enough medical staff and this aspect contributes to the increase of stress the answers are the following:

\section{The tasks that are not found in the job description and their contribution on stress}

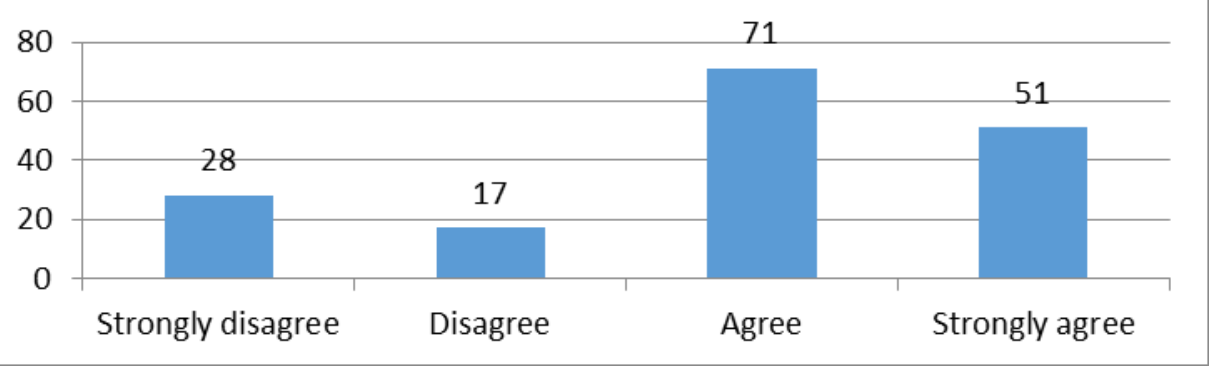

GRAPHIC 3. TASKS NOT FOUND IN JOB DESCRIPTION AND DIRECT CONTRIBUTION TO STRESS

Source: Elaborated by the author 
The most respondents (71 persons) agree that they do tasks that are not found in their job description and this contributes to the increase of the stress. Another 51 persons strongly agree with this affirmation. Most of the respondents consider as a main factor of stress the tasks that they must do and are not mentioned in the job description. This is a result of the insufficient number of the employees.

Another question was regarding the level of the stress and the influence on the personal life. Do you agree that the level of the stress within the workplace has an impact on your personal life?

\section{Do you agree that the stress has an impact on your personal life?}

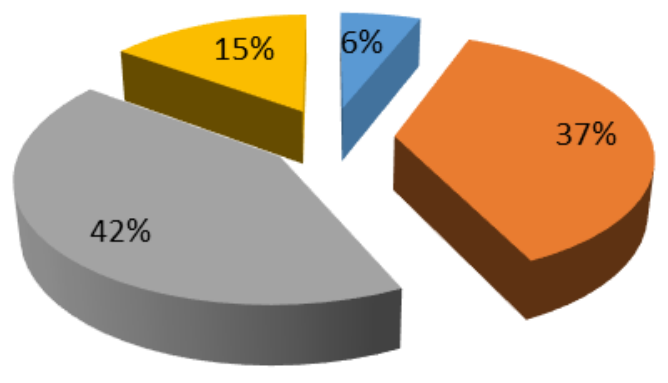

- Strongly disagree

Disagree

Agree

Strongly agree

\section{GRAPHIC 4. STRESS IMPACT IN PERSONAL LIFE}

Source: Elaborated by the author

As it can be seen $42 \%$ of the respondents agree that the stress has an impact on their personal life, $15 \%$ strongly agree with this question and only $6 \%$ strongly disagree. The conclusion is that the personal life of most of the respondents is affected by the organizational stress within their workplace.

How often do you think in your free time at the problems from the work? 


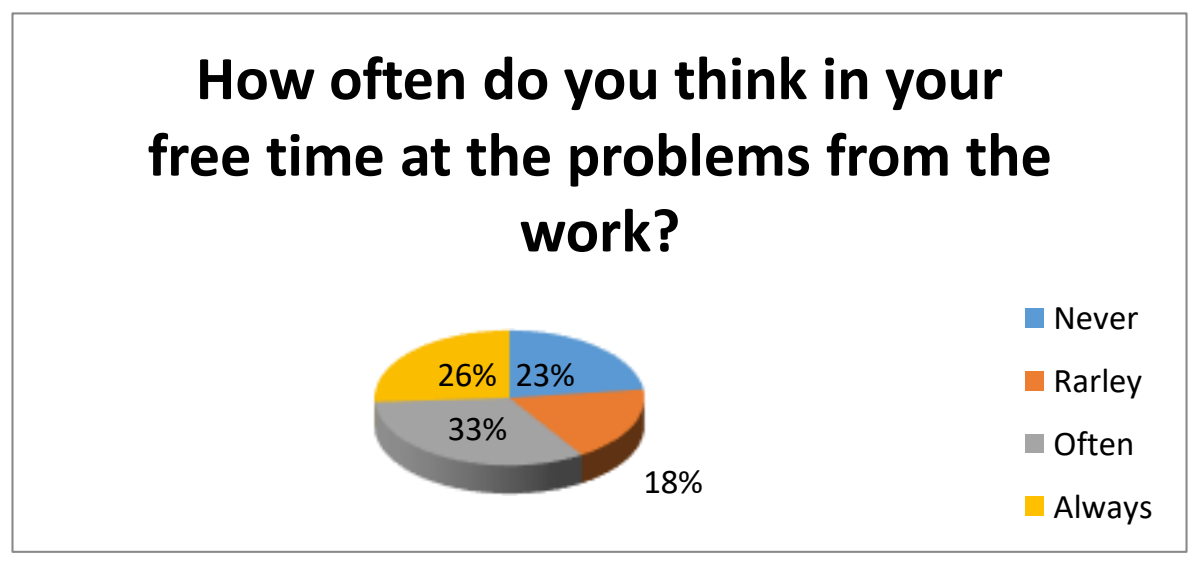

GRAPHIC 5. WORK PROBLEMS' INFLUENCE ON THE FREE TIME

Source: Elaborated by the author

In their free time the most respondents (a percentage of 33\%) are thinking often at the problems from the work and a percentage of $26 \%$ are always thinking at the work problems. At this question the response percentages are close.

To what extent do you agree that a higher level of professional training would contribute to reduce the level of stress at work?

\section{Do you agree that a higher level of professional training would contribute to reduce the level of stress at work?}

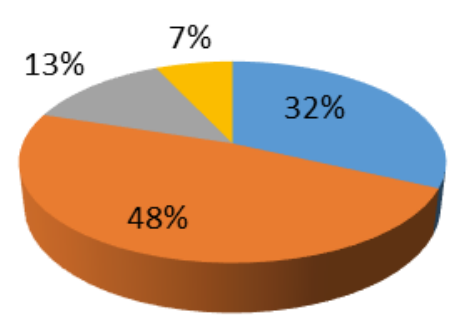

- Strongly disagree

- Disagree

agree

- Strongly agree

GRAPHIC 6. PROFESSIONAL TRAINING LEVEL AND THE CONTRIBUTION TO WORK STRESS

Source: Elaborated by the author

As it can be seen the level of stress is not correlated with the level of professional training. Only $7 \%$ of the respondents consider that a higher level of professional training would contribute to the decrease of the work stress level. 
The both hypotheses were confirmed, because stress is related with work- conditions and stress influence the personal life of the employees. As I wrote before from the employees' responses it seems like the hospital offers good working conditions.

\section{CONCLUSIONS}

The research was concentrated to establish the main stressors factors within the hospital and to determine the impact of stress on personal life of the respondents. The major limitation of this research is the relatively small sample size.

During this period, a lot of things had changed. Coronavirus disease had a great impact on the patients and the staff from health system. The effects could lead to anxiety, worsening and mental distress (Xiang et al., 2020). In the relation physicians- patients the stress adaptation model it is particularly important.

Overall stress was reported by all the respondents. One important conclusion is that a great percentage $(57,48 \%)$ of the respondents are satisfied with the work conditions (96 persons from 167 respondents).

The main stressors factors for the respondents are the complexity of the patient's problems, excessive bureaucracy, and insufficient time to take important decision. As it can be concluded the employees have a lot of work activities and they do not have enough time. Another important factor related to stress is that the respondents are overwhelmed, and they must do more activities that their job description mentioned. The conclusion is that there are not enough employees.

Of them, $42 \%$ consider that organizational stress has an impact on their personal life (almost a half of the respondents) and $26 \%$ are thinking always in their free time at the problems from the work. As it can be seen the stress affects the personal life of the employees.

For reducing stress, it is important to help physicians to maintain work-life balance and to avoid burnout. Also, for the management of the hospital monitoring physicians' satisfaction over time should be a real preoccupation. Also, for reducing stress it the relationship between employee discipline practices and organization culture is a key factor. (Nica, 2013)

It is vital to identify those who are burnout or have psychological distress and staff should be encouraged to step forward without fear of being blamed.

Strategy, structure, culture, and leadership are the four internal dimensions of the organization, explaining the strategic development of human resources contribution to crisis management (Manole et al., 2011) It was found that transformational leadership is significantly related to decreased burnout and decreased overall stress. (Weberg, 2010). 


\section{ACKNOWLEDGMENT}

This work was cofinanced from the European Social Fund through Operational Programme Human Capital 2014-2020, project number POCU/380/6/13/125015 "Development of entrepreneurial skills for doctoral students and postdoctoral researchers in the field of economic sciences"

\section{REFERENCES}

Acker, A., Perry, Z., Reuveni, H., \& Toker, A. (2009). Work satisfaction, quality of life and leisure time of residents at the Soroka University Medical Center, Beer Sheba, Israel. Harefuah, 148(2), 71-5.

Bohannon, N. J., Ohannesian, J. P., Burdan, A. L., Holcombe, J. H., \& Zagar, A. (2000). Patient and physician satisfaction with the Humulin®/Humalog® Pen, a new 3.0-mL prefilled pen device for insulin delivery. Clinical therapeutics, 22(9), 1049-1067.

Ho, C. S., Chee, C. Y., \& Ho, R. C. (2020). Mental health strategies to combat the psychological impact of COVID-19 beyond paranoia and panic. Ann Acad Med Singapore, 49(1), 1-3.

Kahn, R. L., \& Byosiere, P. (1992). Stress in organizations, In M. D. Dunnette \& L. M. Hough (Eds.), Handbook of industrial and organizational psychology (p. 571-650). Consulting Psychologists Press.

Kumar, R., Siddiqui, N., Shahid, Z., Syed, S., \& Kadir, M. (2012). Stress, job satisfaction and work hours in medical and surgical residency programmes in private sector teaching hospitals of Karachi, Pakistan. Journal of Pakistan Medical Association, 62(10), 1109.

Leigh, J. P., Kravitz, R. L., Schembri, M., Samuels, S. J., \& Mobley, S. (2002). Physician career satisfaction across specialties. Archives of internal medicine, 162(14), 1577-1584.

Manole, C., Alpopi, C., \& Colesca, S. E. (2011). The strategic role of human resources development in the management of organizational crisis. Economia. Seria Management, 14(1), 207-221.

Moshe, M., Perry, Z. H., Salzer, L., Zemora, E., \& Toker, A. (2012). Work satisfaction, quality of life, and leisure time of neonatology fellows and senior neonatologists in Israel. Israel journal of health policy research, 1(1), 50.

Nica, E. (2013). Organizational culture in the public sector. Economics, Management, and Financial Markets. 8(2): 179-184.

Nica, E., Manole, C., \& Briscariu, R. (2016). The detrimental consequences of perceived job insecurity on health and psychological well-being. Psychosociological Issues in Human Resource Management, 4(1), 175.

Spitalul Judetean de Urgenta Targoviste, Retrieved January 28, 2020 from https://www.spitaldb.ro/

Tan, B. Y., et al., (2020). Psychological impact of the COVID-19 pandemic on health care workers in Singapore. Annals of Internal Medicine.

Troyer, E. A., Kohn, J. N., \& Hong, S. (2020). Are we facing a crashing wave of neuropsychiatric sequelae of COVID-19? Neuropsychiatric symptoms and potential immunologic mechanisms. Brain, behavior, and immunity.

Wang, C., Pan, R., Wan, X., Tan, Y., Xu, L., McIntyre, R. S., ... \& Ho, C. (2020). A longitudinal study on the mental health of general population during the COVID-19 epidemic in China. Brain, behavior, and immunity. 
Weberg, D. (2010). Transformational leadership and staff retention: an evidence review with implications for healthcare systems. Nursing administration quarterly. 34(3): 246-258.

World Health Organization (WHO). Coronavirus disease 2019 (COVID-19) situation report-51. Geneva, Switzerland: World Health Organization; 2020, Retrieved June 20, 2020 from https://www.who.int/docs/default-source/coronaviruse/situation-reports/20200311-sitrep-51-covid19.pdf?sfvrsn=1ba62e57 10

Xiang, Y. T., Yang, Y., Li, W., Zhang, L., Zhang, Q., Cheung, T., \& Ng, C. H. (2020). Timely mental health care for the 2019 novel coronavirus outbreak is urgently needed. The Lancet Psychiatry, $7(3)$, 228-229. 